\title{
Determination of Mechanical Properties of Aged NPP Components Using Instrumented Hardness Testing and Other Miniature Specimen Testing Techniques
}

\author{
G. B. Lenkey, Sz. Szavai, P. Rozsahegyi, T. Koves, Sz. Jonas, and R. Beleznai \\ Bay Zoltan Nonprofit Ltd., Institute for Logistics and Production Systems, Miskolc, \\ Hungary
}

удК 539.4

\section{Определение механических свойств элементов АЭС после старения с помощью инструментальной оценки твердости и других методов испытания малых образцов}

\author{
Г. Б. Ленкей, Ш. Шаваи, П. Рожахегий, Т. Ковес, Ш. Йонас, Р. Белезнаи \\ Бай Золтан Лтд., Институт логистики и производственных систем, Мишкольц, \\ Венгрия
}

С использованием экспериментальных данных и конечноэлементного моделирования анализируются экспериментальные методы инструментальной оценки твердости и индентирования мальх образиов. Данные методы можно использовать при определении некоторых неизвестных механических свойств материала, когда нет возможности вырезать образць стандартных размеров из исследуемой конструкции.

Ключевые слова: инструментальная оценка твердости, индентирование малых образцов, конечноэлементное моделирование.

Introduction. During the operation of nuclear power plants (NPP) mechanical properties of the structural materials can change due to several factors such as irradiation, temperature, load level and fatigue loading, corrosion, etc. Such a change in material properties influences the lifetime of the equipment (ageing). It is essential for the fitness for service assessment to have reliable information on actual mechanical properties of an operating structure. In most cases, it is not allowed to cut larger pieces from an operating component to manufacture specimens and perform destructive laboratory tests, because it may have significant impact on the component's integrity. The determination of the necessary data is possible with non-destructive or semi-destructive techniques.

1. Instrumented Hardness Test. In several cases, the hardness measurement is the only accepted non-destructive testing method whose results can be used to assess the actual mechanical properties such as yield stress or tensile strength. Since the scatter of the properties calculated directly from the pure hardness value is usually too large and the number of properties to be assessed is limited, methods have been developed for the evaluation of the mechanical properties from the load-indentation curve using instrumented hardness testing. The most reliable 
method is the so-called automated ball indentation (ABI) test [1]. This method requires quite a complex measurement device (Fig. 1) and application on a real structure can be problematic. For handling the difficulties in the case of on-site measurements, a simplified measurement procedure has been implemented for manually operated instrumented hardness tester neglecting the download cycles. The method has been successfully tested on different materials of real components at the Mechanical Testing Laboratory of BAY-LOGI. True stress-true strain curves were derived from the indentation curves and the results were validated with tensile tests and with finite element modeling as well.

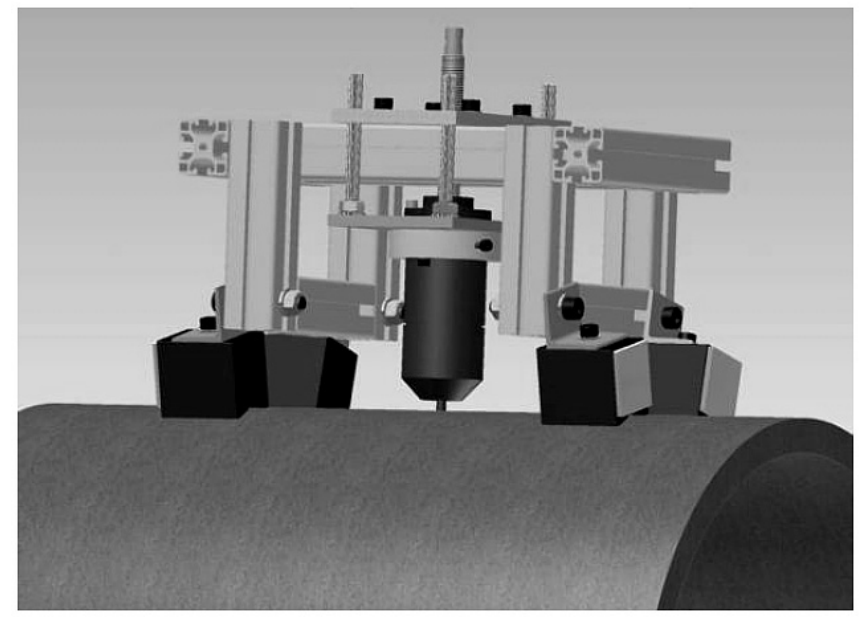

Fig. 1. Instrumented hardness tester on a component.

1.1. Test Parameters and Evaluation Method. The Mat-Tec Unihard S3 type portable instrumented indentation test machine was used, for which an extra aluminum frame was designed and manufactured, in order to clamp the machine properly on the tested equipment surface (Fig. 1). In the case of carbon steel 4 magnet blocks and in the case of austenitic steel two fixing belts could be used. The maximum applied indentation load was $500 \mathrm{~N}$. The indenter was tungsten carbide cone with $1 \mathrm{~mm}$ tip radius. The load and indentation depth curves were recorded and evaluated. The ABI method was used [1] to determine the true stress-true plastic strain curve, the yield stress and the ultimate tensile strength of the tested materials. These parameters were also determined with tensile tests carried out at room temperature and were compared with the indentation test results.

Using the true stress-true strain curve determined with tensile tests and with the indentation tests, the load-indentation depth curve also was determined using finite element methods in order to validate the results obtained from the instrumented hardness testing. Three different material types were tested: austenitic steel, carbon steels with and without Lüders strain. Some kind of statistical analysis was also carried out to determine the uncertainty of the instrumented hardness measurement with conservative approximation.

1.2. Results of the Hardness Test. The results of the finite element method (FEM) validation show that the indentation curves and the finite element results along the loading part of the curve are in good agreement (Fig. 2.) 


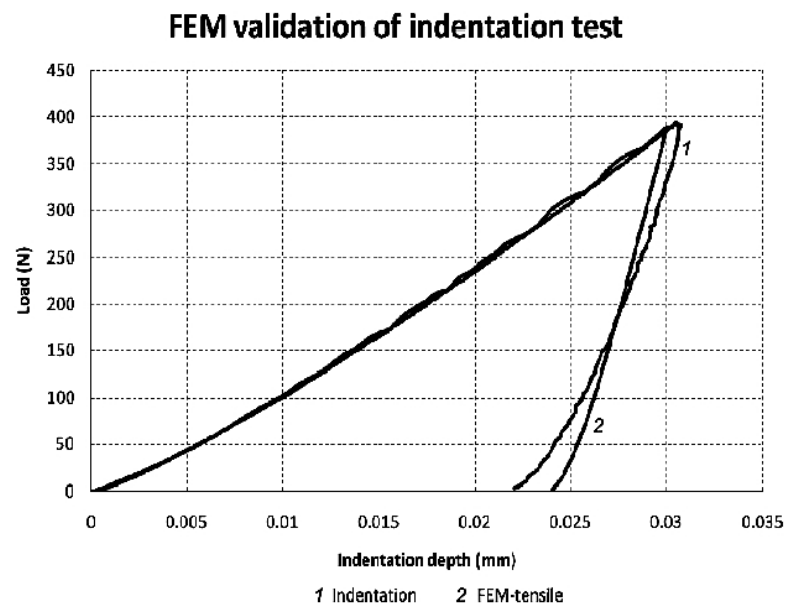

Fig. 2. FEM validation of the evaluation method.

The true stress-true strain curves determined from indentation curves are in good agreement with those determined from tensile tests (Figs. 3-5.). The yield stress and the ultimate tensile strength calculated with ABI method fitted well with the tensile test results. The differences were not more than $3.7 \%$ in the case of yield stress, and $4.5 \%$ in the case of ultimate tensile strength for each tested material type. The calculated measurement uncertainties were $5.85 \%$ for yield stress and $7.46 \%$ for the ultimate tensile strength. The measurement uncertainty calculation was based on a conservative method. To determine this with more accuracy, the work be will continued in the future and more extended analysis of the test parameters will be needed.

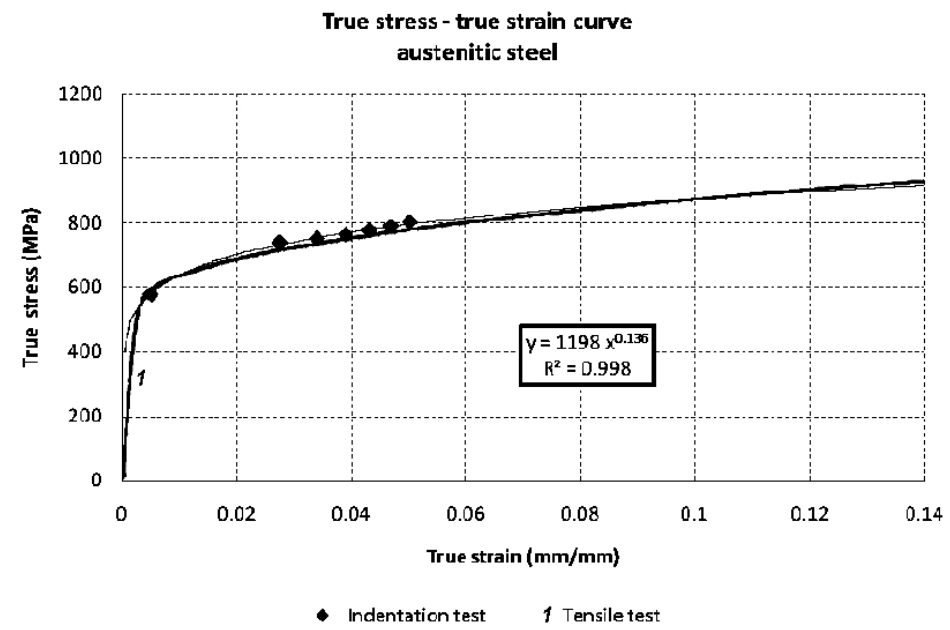

Fig. 3. True stress-true strain curve of austenitic steel.

Despite of the fact that the curves, the yield stress and the ultimate tensile strength calculated with ABI method fitted well with the tensile test results, the results have some scatter and not always provide accurate data for further 


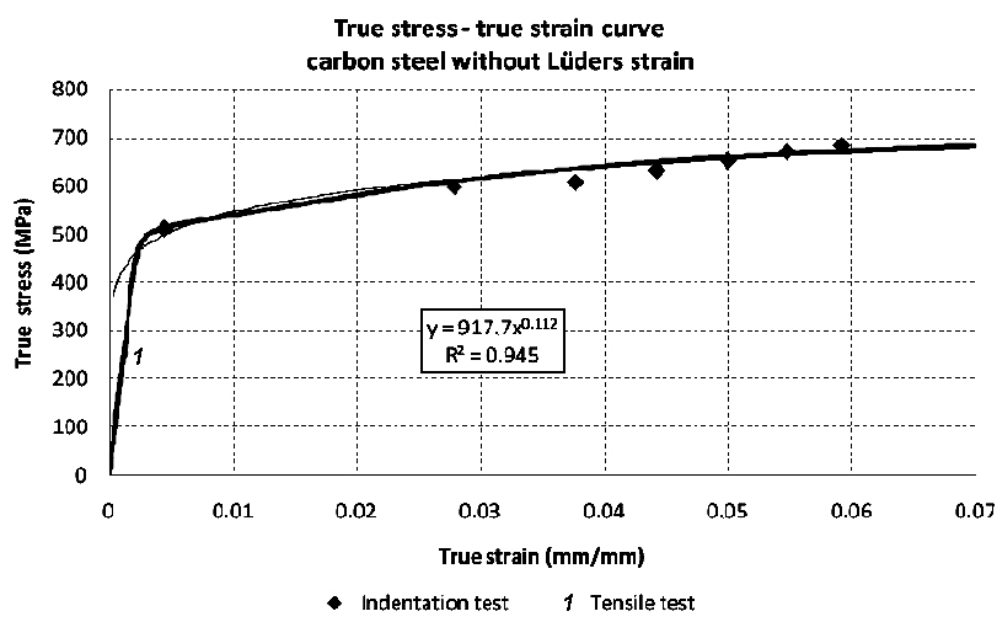

Fig. 4. True stress-true strain curve of carbon steel without Lüders strain.

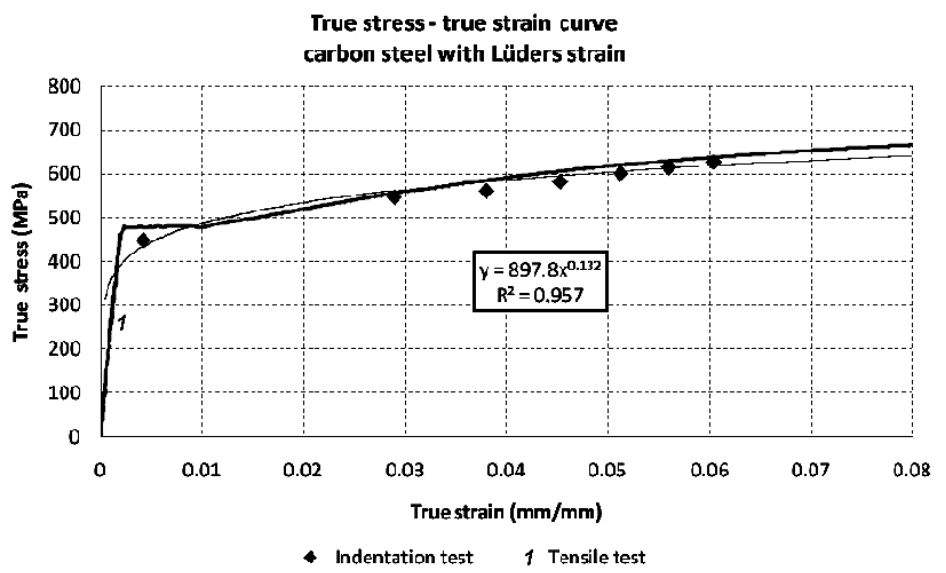

Fig. 5. True stress-true strain curve of carbon steel with Lüders strain.

assessment. Nevertheless, the ABI method does not provide fracture mechanics properties, so other alternative way should be applied. The selected method is the small punch test (SPT), which is one of the miniature specimens' testing techniques and belongs to the semi-destructive testing methods.

2. Small Punch Test. In the framework of a research programme, the small specimen test techniques, like SPT, were studied to understand the size effect and to find an up-to-date measurement technique to assess the ageing problems of structural materials of NPP. The aim of our work was to evaluate the mechanical properties of 15H2MFA, 22K, X6CrNiTi 18-10 (08H18N10T) and their welds and heat-affected zone at room temperature, to compare these data with the results from conventional testing techniques and the above mentioned ABI test. The SPT is a useful technique in residual lifetime assessment owing to the lower tests evaluation cost compared to destructive methods and has higher lifetime evaluation accuracy than the nondestructive test techniques. But the SPT has a disadvantage: the loading originates biaxial stress state in the specimen during the test which causes complication in the determination of the correct material properties. 
The tests have been carried out with the typical specimen size of the SPT. In most literature sources, the SPT specimen has $8 \mathrm{~mm}$ diameter and $0.5 \mathrm{~mm}$ thickness [2] (Fig. 6). The force-displacement curves are registered in each test. The diameter of the ball $(2.5 \mathrm{~mm})$ and also the geometry of the testing clamping device were chosen in accordance with most of the test equipment found in the literature. The SPT was performed according to the guidelines of the European Code of practice [3].

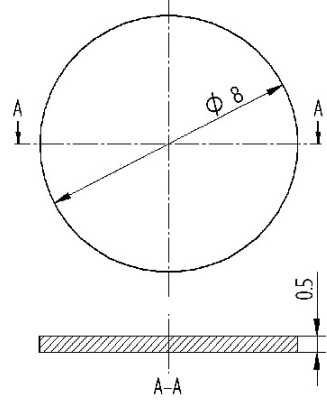

The geometry of the small punch test specimen

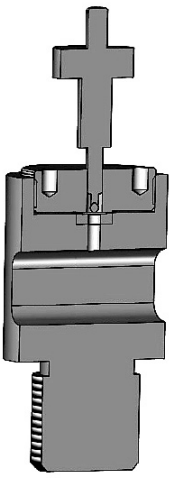

The half of the 3D model of the testing device

Fig. 6. SPT specimen and device.

The aim of the tests was to determine the yield strength of the steels by the so-called two-tangent method from the registered force-displacement curves. The result of the SPT test was validated by finite element method using MSC.Marc\& Mentat code [4].

The typical SP force-displacement curves had four distinct regions (Fig. 7). The first part is the elastic bending, the second is the plastic bending, the third part is the membrane stretching and the last one is the region of plastic instability. The force $P_{y}$ corresponds to the limit of the elastic region and the beginning of the plastic deformation [2]. The tests were made by an Instron 8874 servo-hydraulic biaxial tensile tester machine (Fig. 8) at room temperature. The displacement is measured with an extensometer and a deflection meter at the same time.

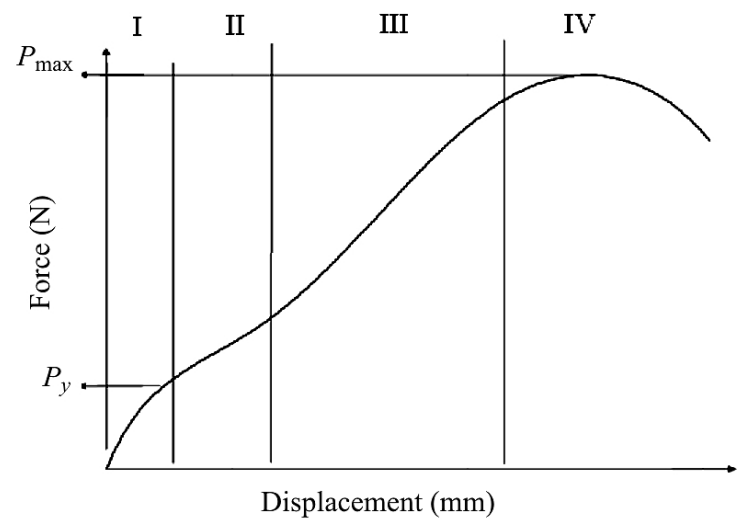

Fig. 7. Typical SP force-displacement curve. 


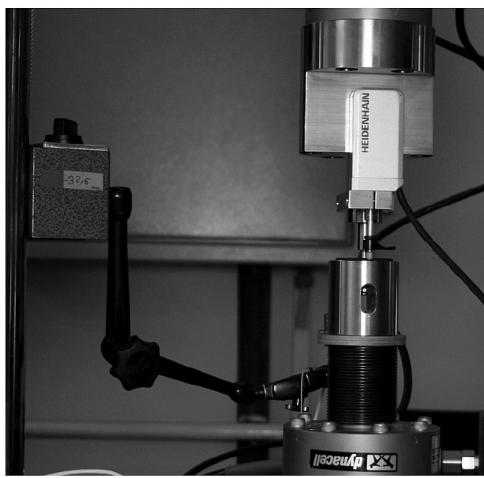

Small punch test

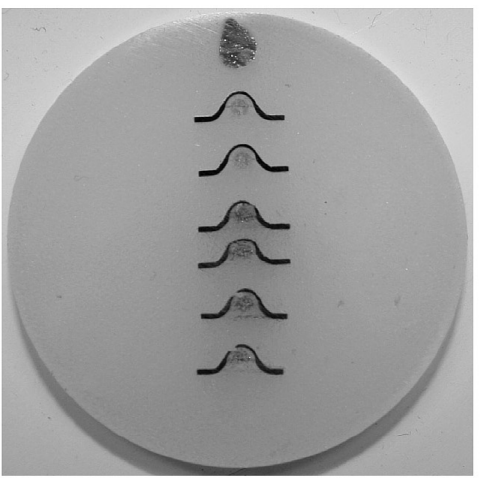

Sections of the specimens

Fig. 8. The testing machine and the sections of the specimens after the test.

2.1. SPT FEM Model. The SPT can be modeled as a 2D axis-symmetric model, because the specimen, the clamping device and the load have cylindrical symmetricity. The model is shown in Fig 9. The conjecture is that the materials with high strength can cause deformation in the testing tool itself, so it is modeled by three parts. The upper die has two parts, because there is a large deviation in the results in the case of high-strength steels. The upper die (Fig. 9, upper die 2/1) can move up $0.1 \mathrm{~mm}$ during the test by the leverage of the specimen. This movement can compensate the deviation in the elastic-bending zone between the measurement and the FEM results. The three parts of the device are linked with a spring to each other in the model to consider the elasticity of the clamping device. The mesh of the lower die is finer than the upper ones, because higher deformation can be expected in the device. The same consideration was taken in the case of the ball and the specimen, too. The ball and the disk were inserted into displacement in the horizontal direction. The puncher is modeled as a rigid contact body and it is represented by a curve which is on the upper part of the ball. Its position is changing during the test. The device, the ball and the SP specimen are modeled as a deformable contact body. The total number of the finite elements in the model is 1213, the specimen has 650 four-node type quadrilateral elements.

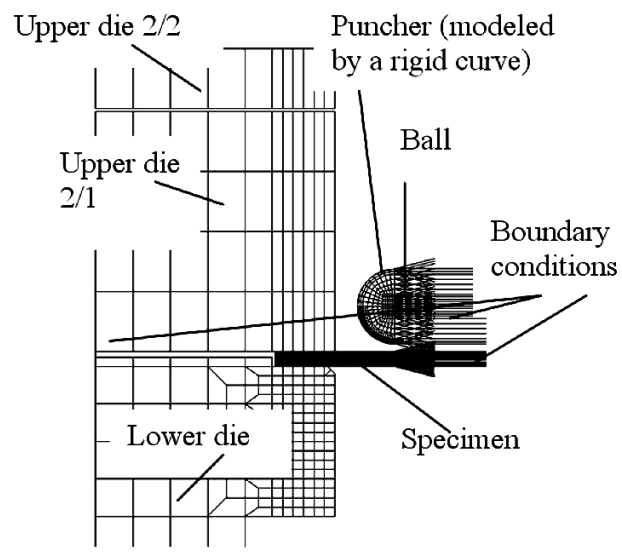

Fig. 9. FEM of the SPT. 
The material properties are defined using true stress-true plastic strain curves, which are obtained by tensile tests. In favour of the more precise results, the curves are extended with a fitting curve in the higher strain value region. The next two diagrams show the hardening curves of the 22K and X6CrNiTi 10-18 (Figs. 10 and 11). The experimental test of the $15 \mathrm{H} 2 \mathrm{MFA}$ material is in process yet and the FEM result is not published here. Figure 12 shows the distribution of the total equivalent plastic strain field in the SP specimen after the test. Making comparison of the force-displacement curves from the test with the FEM analyses, very good agreement can be obtained (Figs. 13 and 14).

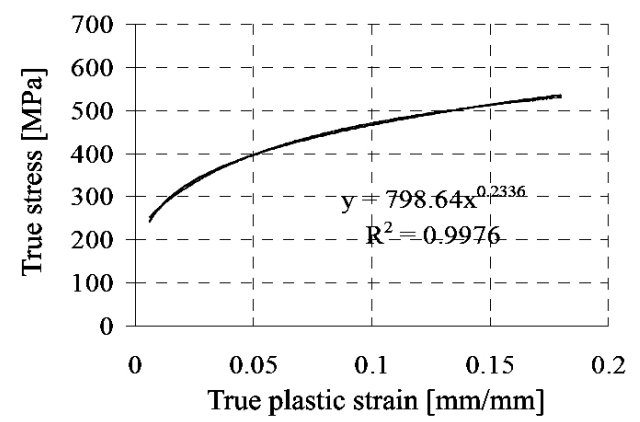

Fig. 10

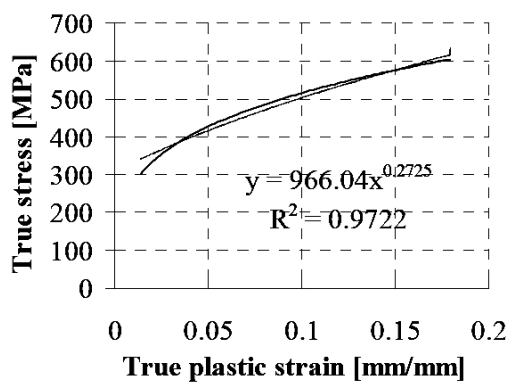

Fig. 11

Fig. 10. True stress-true plastic strain curve (22K).

Fig. 11. True stress-true plastic strain curve (X6CrNiTi 10-18).

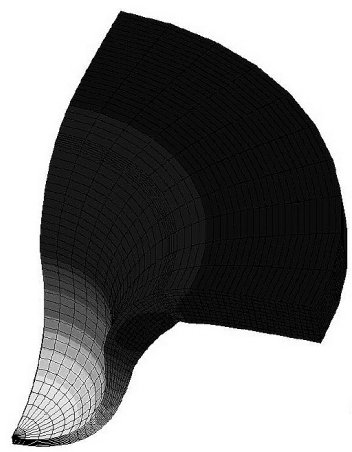

Fig. 12. The total equivalent plastic strain distribution in the specimen after the test.

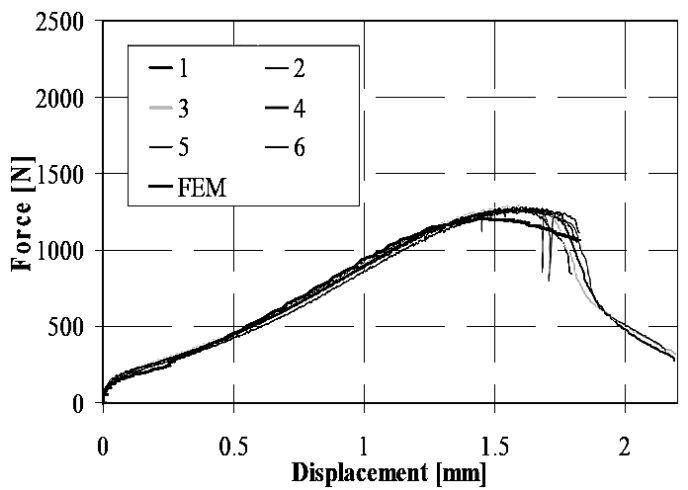

Fig. 13. FEM results comparison with measurement (22K). 


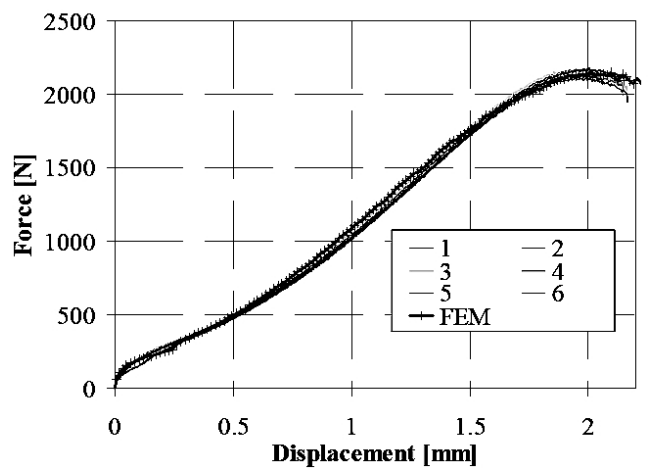

Fig. 14. FEM results comparison with measurement (X6CrNiTi 10-18).

\subsection{Analysis of the Effects of the Friction, the Gap in the Clamping Device} and the Tolerance of the Specimen Thickness. Performing finite element analysis for the clamping device without the $0.1 \mathrm{~mm}$ gap between the upper parts, the results of the test and calculation show a large difference in the first, elastic-bending region. Consideration of the gap in the model provides good agreement between the test and calculation. The expectation of the clamping device deformation proved to be correct. In case of the $22 \mathrm{~K}$ material, the gap is not needed. Consequently, the difference in the strength of the materials causes inaccuracy in the measurement, so the steels with high strength need compensation (Fig. 15). The different friction coefficients are causes difference in the results of the maximum forces as it can be seen in Fig. 16. There is no effect in the elastic-bending region, however, there is large difference in the plastic instability zone. Work [2] provides an equation to determine the tensile strength based on the maximum force from the force-displacement curve, but that expression is valid for larger ball diameter. That equation is derived from 10 types of steels used for power plant components. The tolerance of the specimen thickness $\pm 0.005 \mathrm{~mm}$ is assumed in [5]. The question is that how bigger tolerance affects the results? The results show high dependence on the tolerance of the thickness, so the thickness of the specimens is one of the most important parameter in this test (Figs. 17 and 18). The allowed tolerance causes no deviation, but higher difference in the thickness changes the results, particularly the value of the maximum force.

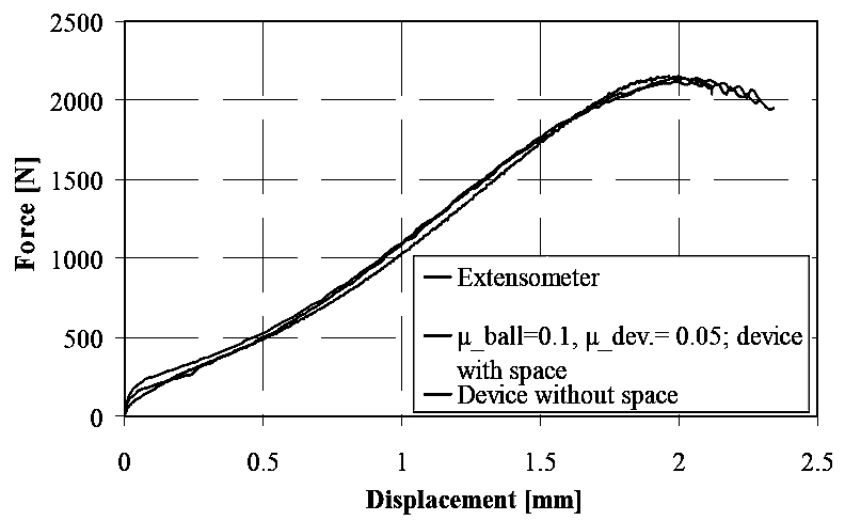

Fig. 15. Effect of the gap in the loading frame. 


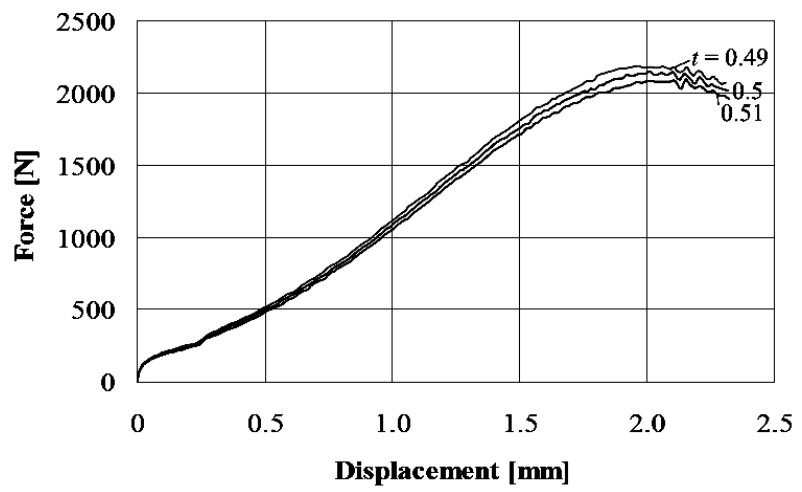

Fig. 16. FEM results of the higher difference than tolerance from the literature.

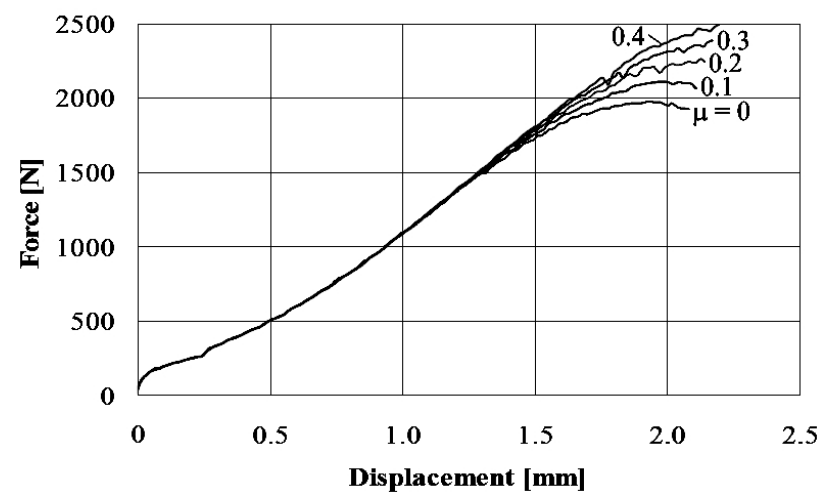

Fig. 17. FEM results for the different friction coefficients.

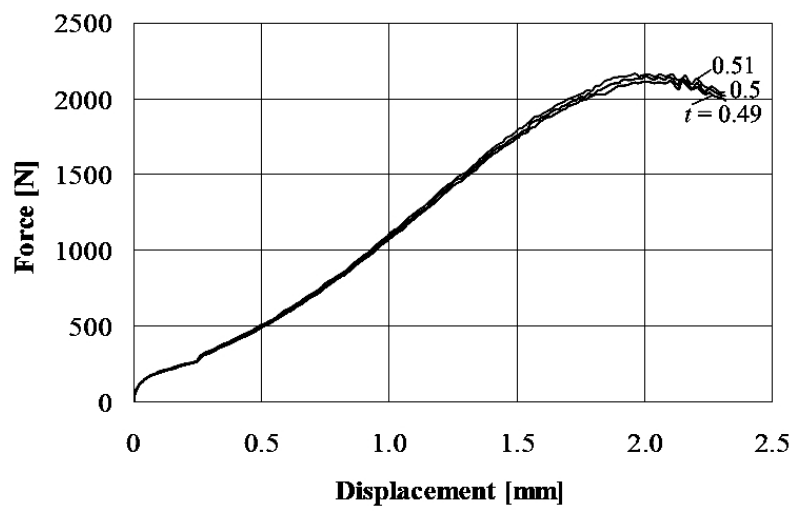

Fig. 18. FEM results for the tolerance of the specimen thickness.

2.3. Determination of the Yield Strength from the SP Curves. There is a new way to evaluate the yield strength of materials [6]. For this the $P_{y}$ value is necessary, which is the maximum load at the upper surface of the specimen when the material properties begin to change, the elastic bending region turns into the plastic bending region (Fig. 7)

$$
\sigma_{0.2}=\alpha \frac{P_{y}}{t^{2}},
$$


where $\alpha$ is the material constant (for X6CrNiTi 10-18, $\alpha=0.477$; for $22 \mathrm{~K}$, $\alpha=0.36), P_{y}$ is the yield load, and $t$ is the thickness of the specimen $(0.5 \mathrm{~mm})$. The comparison of the yield strengths from the Eq. (1) and from tensile tests are presented in Table 1.

$\mathrm{T}$ a b 1 e 1

Comparison of the Measured Yield Strengths

\begin{tabular}{|c|c|c|c||}
\hline Steel & $\begin{array}{c}\text { Yield strength } \\
\text { from SP }(\mathrm{MPa})\end{array}$ & $\begin{array}{c}\text { Yield strength } \\
\text { from FEM (MPa) }\end{array}$ & $\begin{array}{c}\text { Yield strength } \\
\text { from tensile test }(\mathrm{MPa})\end{array}$ \\
\hline 22K & 244 & 245 & 250 \\
\hline X6CrNiTi 10-18 & 270 & 276 & 305 \\
\hline
\end{tabular}

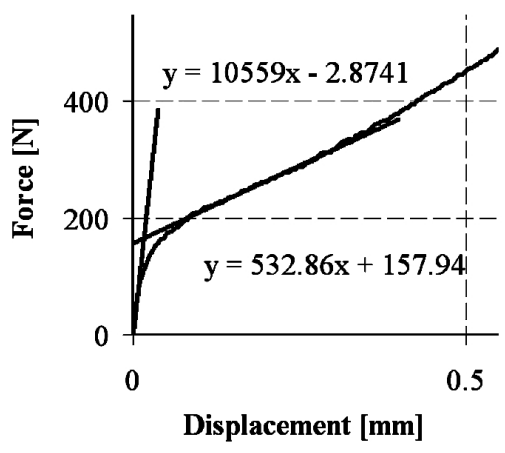

$22 \mathrm{~K}$

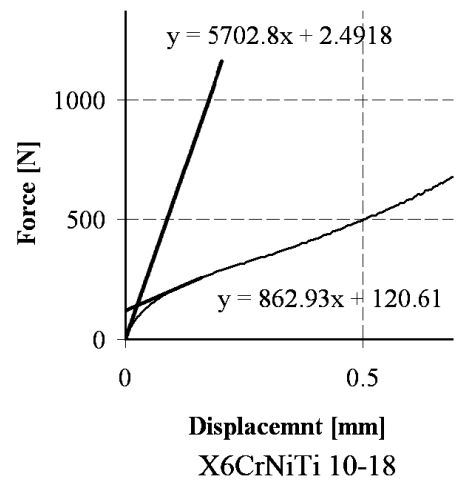

Fig. 19. Determination of the $P_{y}$ yield load from SP curves with two-tangent method.

Two tangent lines should be drawn on the force-displacement curve (one for the elastic-bending zone and the other is for the plastic bending region). Then the intersection point should be projected to the force axis of the diagram. The obtained value is the $P_{y}$ (Fig. 19).

Conclusions. Analyses of the automated ball indentation test and the small punch test are performed using experimental tests and finite element simulation. Both test techniques have been applied for determination of the material properties of NPP structural materials. The ABI test shows some scatter in the results however it is practically applicable when only non-destructive test technique is permitted. The validation of the SPT was also completed and the results from finite element analyses corroborated the measurement results. The yield strength determination shows that the calculation results are good agreement with the results of the tensile tests. These methods can be applied when some material properties are unknown and there is no way to cut larger pieces from the structure to determine them with standard size specimens.

\section{Резиме}

Із використанням експериментальних даних і скінченноелементного моделювання аналізуються експериментальні методи інструментальної оцінки твердості й індентування малих зразків. Дані методи можна використовувати при 
визначенні деяких невідомих механічних властивостей матеріалу, коли немає можливості вирізати зразки стандартних розмірів із досліджуваної конструкції.

1. F. M. Haggag, "In-situ measurements of mechanical properties using novel automated ball indentation system," in: W. R. Corvin, F. M. Haggag, and W. L. Server (Eds.), Small Specimen Test Techniques Applied to Nuclear Reactor Vessel Thermal Annealing and Plant Life Extension, ASTM STP 1204 (1993), pp. 27-44.

2. I. Klevtsov and A. Dedov, "Experience in tensile properties determination by small punch test," in: Proc. 1st Int. Conf. on Determinination of Mechanical Properties of Materials by Small Punch and Other Miniature Testing Techniques (Aug. 31-Sept. 2, 2010, Ostrava, Czech Republic), Metallurg. J., LXIII, Special Issue, 128-132 (2010).

3. R. Hurst and K. Matocha, "The European Code of practice for small punch testing - where do we go from here?," in: Proc. 1st Int. Conf. on Determinination of Mechanical Properties of Materials by Small Punch and Other Miniature Testing Techniques (Aug. 31-Sept. 2, 2010, Ostrava, Czech Republic), Metallurg. J., LXIII, Special Issue, 5-11 (2010).

4. MSC.Marc\&Mentat User's Guide.

5. I. Nonaka, A. Kanaya, S. Komazaki, and K. Kobayashi, "Standardization of test method for small punch creep testing in Japan," in: Proc. 1st Int. Conf. on Determinination of Mechanical Properties of Materials by Small Punch and Other Miniature Testing Techniques (Aug. 31-Sept. 2, 2010, Ostrava, Czech Republic), Metallurg. J., LXIII, Special Issue, 12-18 (2010).

6. P. Du, X. Ling, Z. Zhou, and T. Xu, "Study on influence factors of small punch test to estimate the yield strenght by energy model," in: Proc. 1st Int. Conf. on Determinination of Mechanical Properties of Materials by Small Punch and Other Miniature Testing Techniques (Aug. 31-Sept. 2, 2010, Ostrava, Czech Republic), Metallurg. J., LXIII, Special Issue, 133-137 (2010). 